\title{
Role of reactive oxygen species in the synergistic cytotoxicity of safingol-based combination regimens with conventional chemotherapeutics
}

\author{
LEONG-UUNG LING, KUAN-BOONE TAN and GIGI N.C. CHIU
}

Department of Pharmacy, Faculty of Science, National University of Singapore, Singapore 117543, Republic of Singapore

Received January 5, 2011; Accepted June 1, 2011

DOI: $10.3892 / \mathrm{ol} .2011 .330$

\begin{abstract}
Exploiting the sensitivity of cancer cells to reactive oxygen species (ROS) has been suggested as a strategy for the selective elimination of cancer cells. In this study, the ROS-generating sphingolipid safingol was combined with various conventional chemotherapeutics, and the potential synergism of the safingol-based combination regimen was assessed using a panel of cancer cell lines. The $\mathrm{IC}_{50}$ values of safingol using as a single agent were 1.4-6.3 $\mu \mathrm{M}$, which are concentrations that are clinically achievable. While synergism was dependent on the drug molar ratios, a 4:1 molar ratio of safingol to conventional chemotherapeutics exhibited a moderate to strong synergism in MDA-MB-231, JIMT-1, SKOV-3, U937 and KB cells, with combination indices ranging from 0.07 to 0.77 . Furthermore, the addition of safingol may reduce the concentrations of conventional chemotherapeutics required to achieve $90 \%$ cell-kill by 1 to $>3$ log-folds A significant reduction in the cytotoxicity of safingol-based drug combinations was observed in the presence of $\mathrm{N}$-acetylL-cysteine, suggesting that ROS is an important factor in mediating the observed synergism. Taken together, our results suggest that the use of safingol-based drug combinations is promising as an effective strategy for cancer therapy and should be investigated.
\end{abstract}

\section{Introduction}

Increased oxidative stress has been observed in cancer cells as compared to normal cells $(1,2)$. Lines of evidence include oxidized DNA found in clinical solid tumor specimens $(3,4)$ and the overexpression of anti-oxidant enzymes in cancer cells $(5,6)$. This higher intrinsic oxidative stress is a result of the overproduction of reactive oxygen species (ROS), potentially

Correspondence to: Dr Gigi N.C. Chiu, Department of Pharmacy, Faculty of Science, National University of Singapore, Block S4, 02-09, 18 Science Drive 4, Singapore 117543, Republic of Singapore E-mail: phacncg@nus.edu.sg

Key words: safingol, anti-cancer drugs, drug combination, synergism, reactive oxygen species through a number of mechanisms. These mechanisms include oncogenes such as c-myc and ras, which signal to produce ROS through NADPH oxidase, stimulating cell proliferation $(7,8)$ as well as mutations in mitochondrial DNA, which have been shown to increase ROS in primary leukemia cells (9). The intrinsic oxidative stress of cancer cells renders the cells particularly vulnerable to ROS insults $(1,2)$. Therefore, manipulating ROS levels may facilitate the selective killing of cancer cells, and various strategies used to achieve this killing have been described in the review by Pelicano et al, including direct ROS generation, glutathione depletion and anti-oxidant enzyme inhibition (10).

Safingol is an inducer of autophagy currently under investigation as part of a combination regimen with cisplatin in a Phase I clinical trial for advanced solid tumors (11). Structurally, safingol is the L-threo isomer of dihydrosphingosine $(12,13)$ and is a synthetic and saturated sphingoid base with 18 carbons. The mechanisms of safingol-induced cancer cell death are complex and safingol has often been described as an inhibitor of protein kinase $\mathrm{C}$ (PKC) and sphingosine kinase (SK) $(14,15)$. Previously, our group and other authors demonstrated that the cytotoxic effect of safingol, when used at physiologically relevant concentrations $(5-10 \mu \mathrm{M})$, may not be mediated through PKC inhibition $(16,17)$. Notably, previous studies demonstrated that safingol acts as a ROS-generating agent in fungi and plant cells $(18,19)$.

Combination therapies have been the cornerstone of cancer therapy in clinical practice and safingol has been investigated as part of combination drug regimens. Several in vitro and in vivo studies demonstrated the ability of safingol to enhance the anti-cancer efficacy of other chemotherapeutic agents, including $\mathrm{N}$-(4-hydroxy-phenyl)retinamide (fenretinide), mitomycin-C, cisplatin, $1-\beta-D$-arabinofuranosylcytosine (ara-C) and vinblastine in a variety of tumor cell lines $(13,17,20-24)$. Safingol could potentiate apoptosis induced by conventional chemotherapeutics via the inhibition of PKC and/or modulation of other signaling pathways such as MAPK and JNK/ SAPK $(21,22)$. However, the underlying mechanism for the enhancement effect of safingol remains unknown.

In light of the above findings, the hypothesis of the current study is that safingol exhibits synergistic cytotoxicity with conventional chemotherapeutics via the modulation of ROS in cancer cells. The conventional chemotherapeutics to be 
combined with safingol, i.e., carboplatin, doxorubicin, gemcitabine and vincristine, were selected based on their ability to generate ROS (25-30). Examination of the treatment outcomes of various safingol-based combination regimens was performed based on the application of the combination index (CI) developed by Chou and Talalay, which allows quantitative representation of the potential synergism between safingol and the conventional chemotherapeutic agents (31). Future developments in the field of safingol-based therapeutics may aid scientists and clinicians in the tailoring of various therapies to trigger different modes of cell death in tumor cells.

\section{Materials and methods}

Reagents. Safingol was purchased from Sigma (St. Louis, MO, USA) and dissolved in ethanol. Stock solutions of $2 \mathrm{mg} / \mathrm{ml}$ were stored at $-20^{\circ} \mathrm{C}$ and were freshly diluted with medium to the appropriate concentrations prior to use in the experiments. Carboplatin $10 \mathrm{mg} / \mathrm{ml}$ (Pharmachemie BV, The Netherlands), doxorubicin hydrochloride $2 \mathrm{mg} / \mathrm{ml}$ (Pfizer, Bentley WA, Australia), gemcitabine $40 \mathrm{mg} / \mathrm{ml}$ (Lilly France SAS, France) and vincristine $1 \mathrm{mg} / \mathrm{ml}$ (Sigma) were obtained from the National University Hospital, Singapore. All other chemicals used in the study were purchased from Sigma Chemical Company unless otherwise stated.

Cell cultures. The human breast cancer cell line (MDA-MB231), ovarian cancer cell line (SKOV-3), leukemic cell lines (U937) and nasopharynx cell line (KB) were purchased from the American Type Culture Collection (Manassas, VA, USA). JIMT-1 cells were obtained from DSMZ - Deutsche Sammlung von Mikroorganismen und Zellkulturen GmbH (Braunschweig, Germany). Stock cultures of all cancer cell lines were maintained as monolayer in $75-\mathrm{cm}^{2}$ tissue culture flasks (Iwaki, Japan). MDA-MB-231, U937 and KB cells were cultured in Roswell Park Memorial Institute 1640 (RPMI-1640) medium; JIMT-1 in Dulbecco's modified Eagle's medium F12 (DMEM F12) and SKOV-3 in McCoy 5A medium. All media were supplemented with $10 \%$ v/v fetal bovine serum (FBS; HyClone Laboratories, Logan, UT, USA), 0.3 g/l L-glutamine, 100 U/ml penicillin and $100 \mu \mathrm{g} / \mathrm{ml}$ streptomycin. The cell lines were maintained in a humidified, $5 \% \mathrm{CO}_{2}$ incubator at $37^{\circ} \mathrm{C}$ and subcultured twice weekly using $0.25 \% \mathrm{v} / \mathrm{v}$ trypsin/EDTA (Gibco, Grand Island, NY, USA). Experiments were performed using cells in exponential growth phase from passage 5 to 20 after thawing from frozen stock.

Cell viability assay. Viability of the cancer cells following drug treatment was determined using the colorimetric 3-(4,5-dimethylthiazol-2-yl)-2,5-diphenyl tetrazolium bromide (MTT) assay. Briefly, cells were plated at 5,000/well in 96-well plates and allowed to adhere overnight before exposure to safingol, carboplatin, doxorubicin, gemcitabine or vincristine alone or as fixed molar ratio combinations of safingol:drugs at 1:4 and 4:1. In some of the experiments, $5-10 \mathrm{mM}$ of N-acetyl-Lcysteine (NAC) was added with the drugs. The plates were then incubated for 48 or $72 \mathrm{~h}$ at $37^{\circ} \mathrm{C}$. At the end of the incubation, $50 \mu \mathrm{l}$ MTT ( $1 \mathrm{mg} / \mathrm{ml}$ in media) was added to cells and incubated for $4 \mathrm{~h}$. The MTT-containing medium was then removed and the purple formazan precipitate was solubilized in DMSO.
Absorbance $(\lambda=570 \mathrm{~nm})$ was measured in a microtiter plate reader (Tecan, Infinite M2000 model). Assays were performed in triplicate unless otherwise stated.

Cancer cell viability was calculated based on the absorbance readings using the equation: viability $=\left[\left(\mathrm{Abs}_{\text {test }}-\mathrm{Abs}_{\text {blank }}\right) /\right.$ $\left.\left(\mathrm{Abs}_{\text {vehicle control }}-\mathrm{Abs}_{\text {blank }}\right)\right] \times 100 \%$, where $\mathrm{Abs}_{\text {test }}, \mathrm{Abs}_{\text {blank }}$, $\mathrm{Abs}_{\text {vehicle control }}$ are the absorbance readings from the drug-treated wells, the medium-only wells and the vehicle control wells, respectively. Using the median effect principle described by Chou and Talalay (31), the potency of the drugs was reflected by the median dose $\left(D_{m}\right)$ values, which were estimated using CalcuSyn 3.0 software (Biosoft, Cambridge, UK). For drug combination experiments, results obtained from the MTT assay were used to compute the CI values using the equation below, with the assumption that the drug combinations were mutually exclusive: $\mathrm{CI}=\left[(\mathrm{D})_{1} /\left(\mathrm{D}_{\mathrm{x}}\right)_{1}\right]+\left[(\mathrm{D})_{2} /(\mathrm{Dx})_{2}\right]$, where (D) ${ }_{1}$ and (D) $)_{2}$ are the concentrations of drugs 1 and 2, respectively, which inhibit $\mathrm{x} \%$ in the actual experiment when used in combination. $\left(\mathrm{D}_{\mathrm{x}}\right)_{1}$ and $\left(\mathrm{D}_{\mathrm{x}}\right)_{2}$ are the concentrations of drugs 1 and 2 , respectively, which inhibit $x \%$ in the actual experiment when used as single agents. A CI of $<1, \sim 1$ or $>1$ is indicative of a synergistic, additive or antagonistic interaction for a drug combination, respectively.

Statistical analysis. Data values are reported as the mean \pm standard error (SEM). Statistical differences were determined using the one-way analysis of variance (ANOVA) with the Newman-Keuls test used for post-hoc multiple comparisons. $\mathrm{P}<0.05$ were considered to be statistically significant.

\section{Results}

Effect of safingol as a single agent in human cancer cell lines. The biological effect of safingol on various human cancer cell lines was examined. Cell viability was determined using MTT assay. After 72-h safingol exposure, the viability of cancer cells was reduced in a concentration-dependent manner (Fig. 1). As shown in Table I, safingol was most potent in SKOV-3, an ovarian cancer cell line, with an $\mathrm{IC}_{50}$ of $1.4 \pm 0.18 \mu \mathrm{M}$. The $\mathrm{IC}_{50}$ values of safingol in breast, ovarian, leukemic and nasopharynx cancer cell lines are within the same order of magnitude, ranging from 1.4-6.3 $\mu \mathrm{M}$. Notably, these $\mathrm{IC}_{50}$ values may be achieved in the bloodstream according to a pilot Phase I study (24). Compared to doxorubicin, gemcitabine or vincristine, safingol was less potent in the respective cell lines tested (Table I). However, safingol was more potent by $\sim 7.9$-fold than carboplatin in KB cells (Table I).

Effect of fixed ratio combinations of safingol and conventional chemotherapeutic agents. Fixed molar ratio combinations (1:4 and 4:1) of safingol and chemotherapeutic agents were examined with at least six serially diluted drug concentrations in the respective cell lines. The measure of synergy between safingol and the cytotoxic drugs was determined by the CI values (31). The CI values and the magnitude of dose reductions were estimated at an effect level of $90 \%$ cell-kill for the various ratios, as shown in Table II and Fig. 2, respectively. Three observations were made. First, a ratio-dependent CI profile was observed (Table II). Notably, a 4:1 molar ratio of safingol with carboplatin, doxorubicin, gemcitabine and 
Table I. $\mathrm{IC}_{50}$ values of safingol and conventional anti-cancer drugs in respective cancer cell lines.

\begin{tabular}{lccccc}
\hline Cell lines & Safingol $(\mu \mathrm{M})$ & Doxorubicin $(\mu \mathrm{M})$ & Gemcitabine $(\mu \mathrm{M})$ & Carboplatin $(\mu \mathrm{M})$ & Vincristine $(\mu \mathrm{M})$ \\
\hline MDA-MB-231 & $4.4 \pm 1.0$ & $0.71 \pm 0.15^{\mathrm{a}}$ & $0.22 \pm 0.08^{\mathrm{a}}$ & - & - \\
JIMT-1 & $2.8 \pm 0.45$ & $0.43 \pm 0.07^{\mathrm{a}}$ & $0.07 \pm 0.03^{\mathrm{a}}$ & - & - \\
SKOV-3 & $1.4 \pm 0.18$ & $0.60 \pm 0.14$ & $0.20 \pm 0.12^{\mathrm{a}}$ & - & - \\
KB & $6.3 \pm 1.3$ & - & - & - & $0.0011 \pm 0.00027^{\mathrm{a}}$ \\
U937 & $2.4 \pm 0.1$ & - & - & -
\end{tabular}

Cell viability was determined by MTT assay and subsequently analyzed by CalcuSyn 3.0 software to estimate $\mathrm{IC}_{50}$ values. Each reported value is the mean \pm SEM from three independent experiments. $r$-values were $\geq 0.9 .{ }^{a} p<0.05$, significantly different from the safingol-treated group.

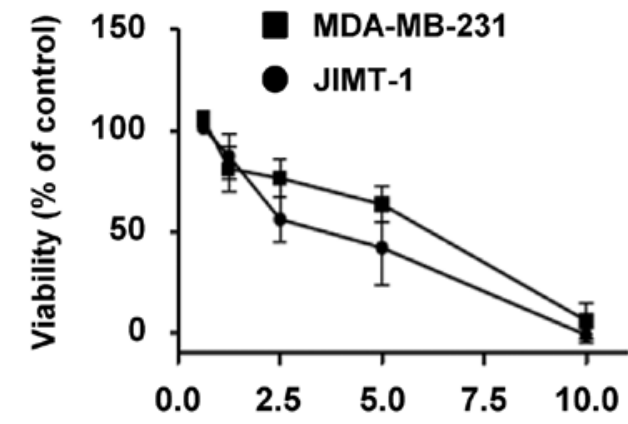

Safingol $(\mu \mathrm{M})$

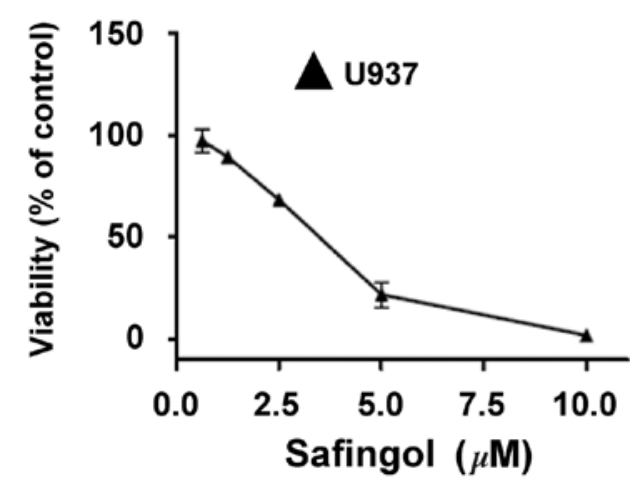

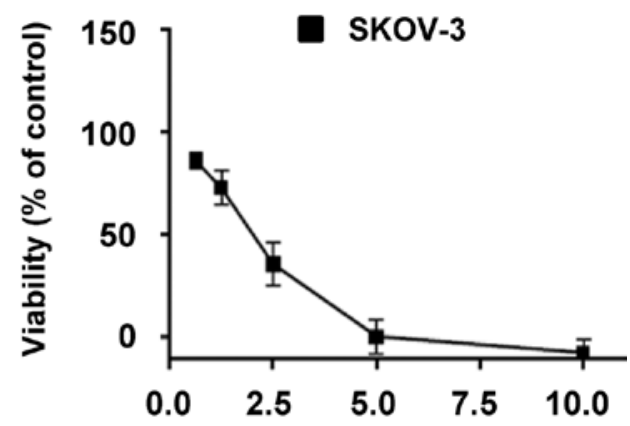

Safingol $(\mu \mathrm{M})$

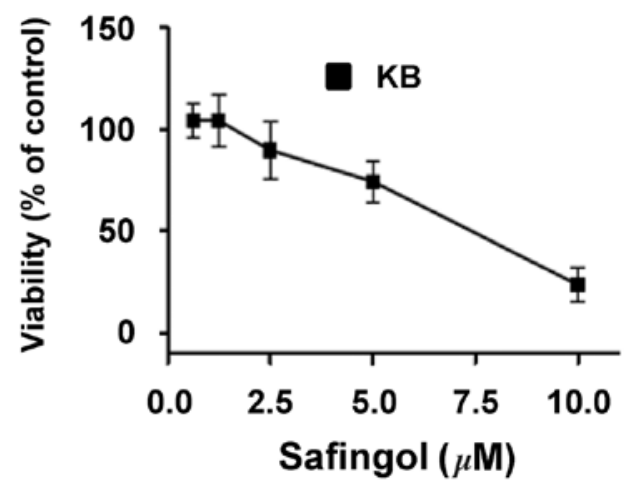

Figure 1. Effects of safingol treatment on the viability of different cancer cell lines. Cells were treated with safingol for 72 h. Viability was assessed using MTT assay. Results shown are the means \pm SEM from three independent experiments.

vincristine consistently provided synergy in the respective cell lines (Table II). Among these safingol-based combinations, the safingol/gemcitabine (4:1) combination showed the strongest synergism, with a CI value of 0.07 in SKOV-3 cells (Table II). On the other hand, safingol/gemcitabine at 1:4 molar ratio showed antagonism in MDA-MB-231 and JIMT-1, as shown by the CI values $>1$ (Table II). These results supported the hypothesis that the treatment outcome of drug combinations were highly dependent on the molar ratios of the individual agents (32). Second, substantial dose reduction of safingol and chemotherapeutic agents was achieved when used in combination as compared to the administration of individual agents (Fig. 2). In particular, when safingol and gemcitabine were used at a $4: 1$ molar ratio, the concentration of gemcitabine required to achieve $90 \%$ cell-kill in SKOV-3 cells was reduced by more than 3 log-folds (Fig. 2). Third, safingol was able to act synergistically with different classes of chemotherapeutic agents in various cell lines (Table II).

Role of ROS in safingol-based combination drug regimens. To examine whether ROS generation was responsible for the synergism observed in safingol-based drug combinations, 4:1 molar ratios of safingol/carboplatin, safingol/doxorubicin, safingol/ gemcitabine and safingol/vincristine were further evaluated in KB, MDA-MB-231, SKOV-3 and U937 cells, respectively, with or without the presence of the ROS scavenger NAC. These drug combinations were selected as they demonstrated the most promising results based on their CI values in their respective classes of anti-cancer drugs (Table II). As expected, the percentage of viable cells was increased when ROS was 
Table II. Combination indices of safingol with different classes of anti-cancer drugs in respective cancer cell lines.

\begin{tabular}{|c|c|c|c|c|c|}
\hline Safingol+ & Cell line & Molar ratio of safingol/drug & $\mathrm{CI}_{90}$ & $\mathrm{r}$ & Interaction \\
\hline \multicolumn{6}{|c|}{ Alkylating agent } \\
\hline Carboplatin & $\mathrm{KB}$ & $\begin{array}{l}1: 4 \\
4: 1\end{array}$ & $\begin{array}{l}0.96 \\
0.77\end{array}$ & $\begin{array}{l}0.96 \\
0.98\end{array}$ & $\begin{array}{c}\text { Additive } \\
\text { Synergistic }\end{array}$ \\
\hline \multicolumn{6}{|l|}{ Anthracycline } \\
\hline \multirow[t]{3}{*}{ Doxorubicin } & MDA-MB-231 & $\begin{array}{l}1: 4 \\
4: 1\end{array}$ & $\begin{array}{l}0.56 \\
0.28\end{array}$ & $\begin{array}{l}0.90 \\
0.84\end{array}$ & $\begin{array}{l}\text { Synergistic } \\
\text { Synergistic }\end{array}$ \\
\hline & JIMT-1 & $\begin{array}{l}1: 4 \\
4: 1\end{array}$ & $\begin{array}{l}0.46 \\
0.42\end{array}$ & $\begin{array}{l}0.96 \\
0.84\end{array}$ & $\begin{array}{l}\text { Synergistic } \\
\text { Synergistic }\end{array}$ \\
\hline & SKOV-3 & $\begin{array}{l}1: 4 \\
4: 1\end{array}$ & $\begin{array}{l}0.44 \\
0.61\end{array}$ & $\begin{array}{l}0.98 \\
0.92\end{array}$ & $\begin{array}{l}\text { Synergistic } \\
\text { Synergistic }\end{array}$ \\
\hline \multicolumn{6}{|l|}{ Antimetabolite } \\
\hline \multirow[t]{3}{*}{ Gemcitabine } & MDA-MB-231 & $\begin{array}{l}1: 4 \\
4: 1\end{array}$ & $\begin{array}{l}2.10 \\
0.55\end{array}$ & $\begin{array}{l}0.99 \\
0.97\end{array}$ & $\begin{array}{c}\text { Antagonistic } \\
\text { Synergistic }\end{array}$ \\
\hline & JIMT-1 & $\begin{array}{l}1: 4 \\
4: 1\end{array}$ & $\begin{array}{l}1.40 \\
0.49\end{array}$ & $\begin{array}{l}0.93 \\
0.95\end{array}$ & $\begin{array}{c}\text { Antagonistic } \\
\text { Synergistic }\end{array}$ \\
\hline & SKOV-3 & $\begin{array}{l}1: 4 \\
4: 1\end{array}$ & $\begin{array}{l}1.00 \\
0.07\end{array}$ & $\begin{array}{l}0.90 \\
0.95\end{array}$ & $\begin{array}{c}\text { Additive } \\
\text { Synergistic }\end{array}$ \\
\hline \multicolumn{6}{|l|}{ Vinca alkaloids } \\
\hline Vincristine & U937 & $\begin{array}{l}1: 4 \\
4: 1\end{array}$ & $\begin{array}{l}0.39 \\
0.24\end{array}$ & $\begin{array}{l}0.90 \\
0.94\end{array}$ & $\begin{array}{l}\text { Synergistic } \\
\text { Synergistic }\end{array}$ \\
\hline
\end{tabular}

Viability of cancer cells was probed with MTT assay after exposure to various combination regimens. At least six concentrations of drugs were used for the analysis of the pharmacological interactions for each molar drug ratio in the respective cell lines. MTT viability data were pooled from three independent studies and used to compute the CI values using CalcuSyn 3.0 software. The reported CI values were based on the drug concentration required to achieve $90 \%$ cell-kill. $\mathrm{CI}<1, \sim 1$ and $>1$ denote synergistic, additive and antagonistic interaction, respectively. $\mathrm{r}$, the linear correlation coefficient of the median-effect plot.

removed by NAC in all of the cancer cell lines (Fig. 3). These results suggest that ROS plays a critical role in the observed synergism of safingol-based combination drug regimens.

\section{Discussion}

At present, the mainstay of cancer therapy is the use of combination drug regimens. Combinations of safingol with a wide range of conventional chemotherapeutic agents have been examined at specific concentrations. Many of these studies have demonstrated the ability of safingol to enhance the cytotoxic effect of the other agent. However, this approach does not take into consideration the fact that the potential synergistic effect of a combination regimen is highly dependent upon the concentrations and ratios of the combined drugs (32). A formal investigation of the treatment outcomes of various safingol-based combination regimens was performed in this study with the aim of providing information regarding safingol-based combination drug regimens. The approach undertaken was the use of CI, a parameter derived from the Chou and Talalay median effect principle (31). This approach allowed us to determine drug synergism based on a range of drug concentrations and to give quantitative representation of the pharmacological interaction between safingol and the conventional chemotherapeutic agents. In combination with carboplatin, doxorubicin, gemcitabine and vincristine, safingol acts synergistically in killing a variety of cancer cells at specific drug molar ratios. This is therapeutically beneficial since safingol-based combination drug regimens provide an alternative treatment approach in a wide range of malignancies. Furthermore, such synergistic interaction may be mediated by ROS.

Increased ROS levels have been observed in cancer cells $(1,2)$. However, previous studies suggested that this characteristic can be exploited for therapeutic benefits as cancer cells are more dependent on anti-oxidant systems to manage oxidative stress in comparison to normal cells. Thus, additional exogenous ROS, either caused by ROS-generating agents or anti-oxidant inhibitors, are likely to trigger more ROS damage in cancer cells $(10,33)$. The conventional chemotherapeutic drugs used in the present study have been shown to increase ROS production in cancer cells (25-30). Additionally, safingol has been demonstrated to generate ROS in fungi and plant cells $(18,19)$. Our current findings suggest that combining ROS-generating conventional chemotherapeutics with other novel ROS-generating agents, as exemplified by the bioactive sphingolipid safingol, causes a synergistic killing effect in cancer cells. Other sphingolipids, such as short-chained ceramides $\left(\mathrm{C}_{2}\right.$ and $\left.\mathrm{C}_{6}\right)$, have been shown to cause an increase in mitochondrial peroxide production, leading to growth arrest in U937 and apoptosis in Jurkat cells (34). Findings of studies designed to understand the involvement of these bioactive lipids in the signaling of ROS have shown a number of opportuni- 
A

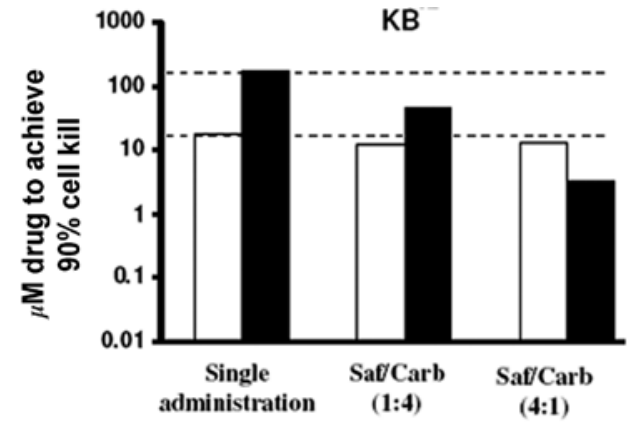

C

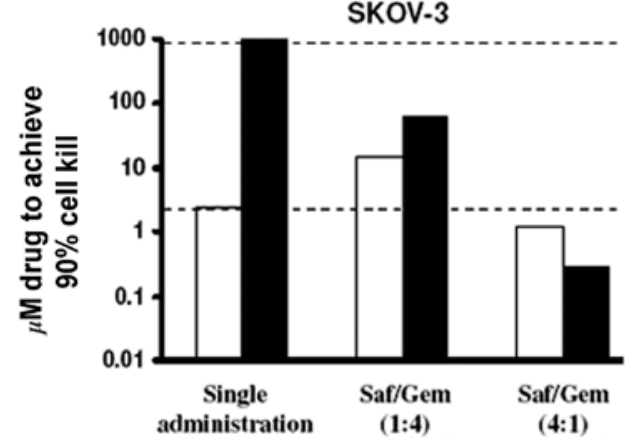

B

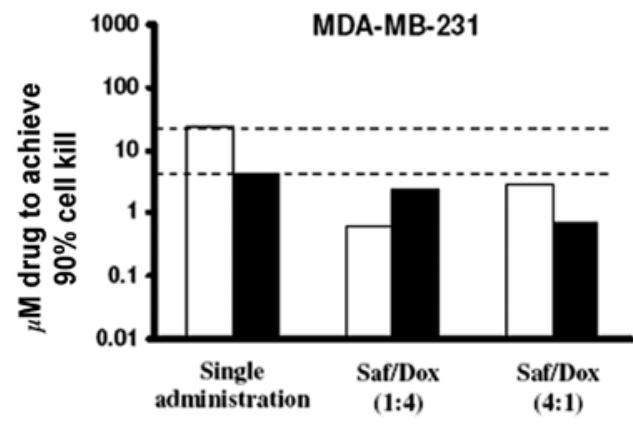

D

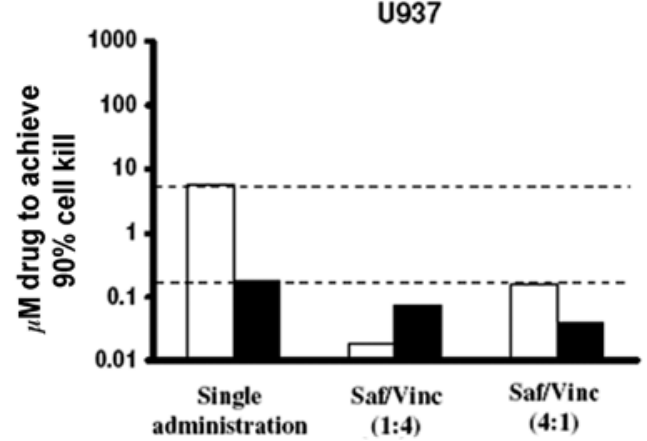

Figure 2. Dose reduction analysis of safingol (Saf)-based drug combinations. The drug concentrations required to achieve $90 \%$ cell-kill for safingol (white bars) and respective anti-cancer drugs (black bars) used alone or in 1:4 and 4:1 fixed molar ratios are shown. (A-D) Carb, carboplatin; Dox, doxorubicin; Gem, gemcitabine; and Vinc, vincristine.

A

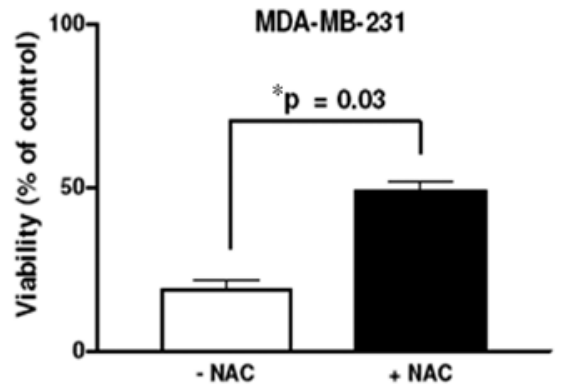

C

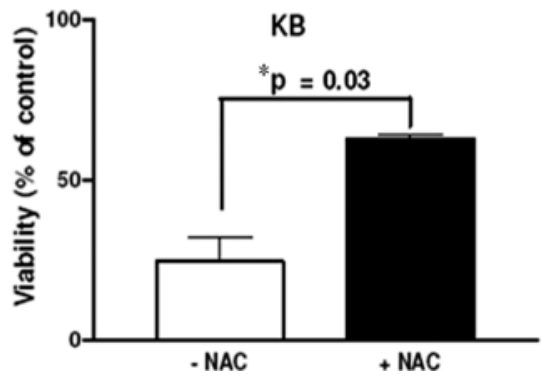

B

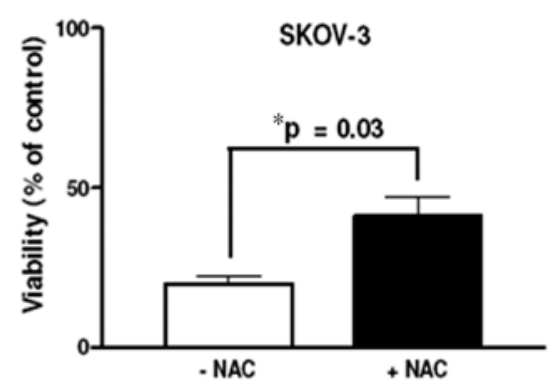

D

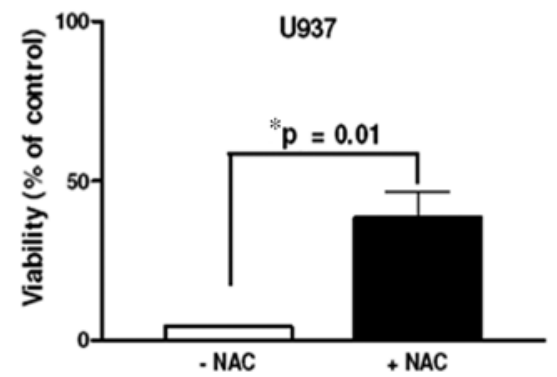

Figure 3. Effect of NAC on safingol-based drug combinations observed in various cancer cell lines. (A-D) Molar ratios (4:1) of safingol/carboplatin, safingol/ doxubicin, safingol/gemcitabine and safingol/vincristine were tested in the absence and presence of $10 \mathrm{mM}$ NAC, with the exception of for U937 cells where $\mathrm{NAC}$ was $5 \mathrm{mM}$. The cells were treated for $48 \mathrm{~h}$. The results were obtained from cells treated with $5 \mu \mathrm{M}$ safingol, with the exception of for KB cells where $10 \mu \mathrm{M}$ safingol was used. Data shown are the means \pm SEM from three independent experiments. "NAC-treated group compared to non-NAC group.

ties for exploiting sphingolipids such as safingol in achieving specific therapeutic objectives.

Notably, cell death induced by safingol-based combination drug regimens was not completely reversed in the presence of NAC, although our results suggested that ROS is a crucial mediator in the observed synergism. These data suggest the involvement of other mediators that may contribute to the observed synergistic cytotoxic effect. Our previous findings showed that PKC inhibition was a possible mechanism for synergistic interaction between safingol and irinotecan (16). 
Since ROS and PKC are important mediators in cellular signaling events that regulate proliferation and death, there may be significant interaction between ROS- and PKC-mediated signaling responses. PKC activation has been shown to up-regulate the anti-oxidant enzyme superoxide dismutase to prevent the accumulation of ROS (35). Notably, ROS generation may in turn activate PKC (36). It is possible that the PKC pathway and ROS act in parallel in the amplification of cell death, and investigation is required to provide further insights into the underlying mechanism for the synergism in safingolbased combination regimens.

\section{Acknowledgements}

This study was supported by Singapore's Ministry of Education through the National University of Singapore (NUS) Academic Research Fund FRC-Tier 1 grant (R-148-000-098-112). L.U. Ling and K.B. Tan are supported by a NUS graduate research scholarship.

\section{References}

1. Kang D and Hamasaki N: Mitochondrial oxidative stress and mitochondrial DNA. Clin Chem Lab Med 41: 1281-1288, 2003.

2. Behrend L, Henderson G and Zwacka RM: Reactive oxygen species in oncogenic transformation. Biochem Soc Trans 31: 1441-1444, 2003.

3. Patel BP, Rawal UM, Dave TK, et al: Lipid peroxidation, total antioxidant status and total thiol levels predict overall survival in patients with oral squamous cell carcinoma. Integr Cancer Ther 6: 365-372, 2007.

4. Tsao SM, Yin MC and Liu WH: Oxidant stress and B vitamins status in patients with non-small cell lung cancer. Nutr Cancer 59: 8-13, 2007.

5. Janssen AM, Bosman CB, Kruidenier L, et al: Superoxide dismutases in the human colorectal cancer sequence. J Cancer Res Clin Oncol 125: 327-335, 1999.

6. Kanbagli O, Ozdemirler G, Bulut T, Yamaner S, Aykac-Toker G and Uysal M: Mitochondrial lipid peroxides and antioxidant enzymes in colorectal adenocarcinoma tissues. Jpn J Cancer Res 91: 1258-1263, 2000.

7. Irani K, Xia Y, Zweier JL, et al: Mitogenic signaling mediated by oxidants in Ras-transformed fibroblasts. Science 275: 1649-1652, 1997.

8. Suh YA, Arnold RS, Lassegue B, et al: Cell transformation by the superoxide-generating oxidase Mox1. Nature 401: 79-82, 1999.

9. Carew JS, Zhou Y, Albitar M, Carew JD, Keating MJ and Huang P: Mitochondrial DNA mutations in primary leukemia cells after chemotherapy: clinical significance and therapeutic implications. Leukemia 17: 1437-1447, 2003.

10. Pelicano H, Carney D and Huang P: ROS stress in cancer cells and therapeutic implications. Drug Resist Updat 7: 97-110, 2004

11. Carvajal RD: A Phase I clinical trial of safingol followed by cisplatin: Promising activity in refractory adrenocortical cancer with novel pharmacology. Proc Amer Soc Clin Oncol 24: 13044, 2006.

12. Dragusin M, Gurgui C, Schwarzmann G, Hoernschemeyer J and van Echten-Deckert G: Metabolism of the unnatural anticancer lipid safingol, L-threo-dihydrosphingosine, in cultured cells. J Lipid Res 44: 1772-1779, 2003.

13. Schwartz G, Jiang J, Kelsen D and Albino A: Protein kinase C: a novel target for inhibiting gastric cancer cell invasion. J Natl Cancer Inst 85: 402-407, 1993.

14. Buehrer BM and Bell RM: Inhibition of sphingosine kinase in vitro and in platelets. Implications for signal transduction pathways. J Biol Chem 267: 3154-3159, 1992.

15. Hannun Y, Loomis $C$ and Bell R: Protein kinase $C$ activation in mixed micelles. Mechanistic implications of phospholipid, diacylglycerol and calcium interdependencies. J Biol Chem 261: 7184-7190, 1986.

16. Ling LU, Lin H, Tan KB and Chiu GN: The role of protein kinase $\mathrm{C}$ in the synergistic interaction of safingol and irinotecan in colon cancer cells. Int J Oncol 35: 1463-1471, 2009.
17. Hoffmann T, Leenen K, Hafner D, et al: Antitumor activity of protein kinase $\mathrm{C}$ inhibitors and cisplatin in human head and neck squamous cell carcinoma lines. Anticancer Drugs 13: 93-100, 2002.

18. Cheng J, Park TS, Chio LC, Fischl AS and Ye XS: Induction of apoptosis by sphingoid long-chain bases in Aspergillus nidulans. Mol Cell Biol 23: 163-177, 2003.

19. Shi L, Bielawski J, Mu J, et al: Involvement of sphingoid bases in mediating reactive oxygen intermediate production and programmed cell death in Arabidopsis. Cell Res 17: 1030-1040, 2007.

20. Schwartz G, Haimovitz-Friedman A, Dhupar S, et al: Potentiation of apoptosis by treatment with the protein kinase $\mathrm{C}$-specific inhibitor safingol in mitomycin C-treated gastric cancer cells. J Natl Cancer Inst 87: 1394-1399, 1995.

21. Jarvis W, Fornari FJ, Tombes R, et al: Evidence for involvement of mitogen-activated protein kinase, rather than stress-activated protein kinase, in potentiation of 1-beta-D-arabinofuranosylcytosine-induced apoptosis by interruption of protein kinase C signaling. Mol Pharmacol 54: 844-856, 1998.

22. Maurer B, Melton L, Billups C, Cabot M and Reynolds C: Synergistic cytotoxicity in solid tumor cell lines between $\mathrm{N}$-(4-hydroxyphenyl)retinamide and modulators of ceramide metabolism. J Natl Cancer Inst 92: 1897-1909, 2000.

23. Sachs C, Safa A, Harrison S and Fine R: Partial inhibition of multidrug resistance by safingol is independent of modulation of P-glycoprotein substrate activities and correlated with inhibition of protein kinase C. J Biol Chem 270: 26639-26648, 1995.

24. Schwartz G, Ward D, Saltz L, et al: A pilot clinical/pharmacological study of the protein kinase $\mathrm{C}$-specific inhibitor safingol alone and in combination with doxorubicin. Clin Cancer Res 3: 537-543, 1997.

25. Cheng CF, Juan SH, Chen JJ, et al: Pravastatin attenuates carboplatin-induced cardiotoxicity via inhibition of oxidative stress associated apoptosis. Apoptosis 13: 883-894, 2008.

26. Husain K, Whitworth C, Hazelrigg S and Rybak L: Carboplatininduced oxidative injury in rat inferior colliculus. Int J Toxicol 22: 335-342, 2003.

27. Gewirtz DA: A critical evaluation of the mechanisms of action proposed for the antitumor effects of the anthracycline antibiotics adriamycin and daunorubicin. Biochem Pharmacol 57: 727-741, 1999.

28. Maehara S, Tanaka S, Shimada M, et al: Selenoprotein P, as a predictor for evaluating gemcitabine resistance in human pancreatic cancer cells. Int J Cancer 112: 184-189, 2004.

29. Donadelli M, Costanzo C, Beghelli S, et al: Synergistic inhibition of pancreatic adenocarcinoma cell growth by trichostatin A and gemcitabine. Biochim Biophys Acta 1773: 1095-1106, 2007.

30. Woiniak A, Drewa G, Wozniak B, et al: The effect of antitumor drugs on oxidative stress in B16 and S91 melanoma cells in vitro. Med Sci Monit 11: BR22-29, 2005.

31. Chou TC and Talalay P: Quantitative analysis of dose-effect relationships: the combined effects of multiple drugs or enzyme inhibitors. Adv Enzyme Regul 22: 27-55, 1984.

32. Mayer L, Harasym T, Tardi P, et al: Ratiometric dosing of anticancer drug combinations: controlling drug ratios after systemic administration regulates therapeutic activity in tumor-bearing mice. Mol Cancer Ther 5: 1854-1863, 2006.

33. Hileman EO, Liu J, Albitar M, Keating MJ and Huang P: Intrinsic oxidative stress in cancer cells: a biochemical basis for therapeutic selectivity. Cancer Chemother Pharmacol 53: 209-219, 2004.

34. Phillips DC, Allen K and Griffiths HR: Synthetic ceramides induce growth arrest or apoptosis by altering cellular redox status. Arch Biochem Biophys 407: 15-24, 2002.

35. Kim CH, Han SI, Lee SY, et al: Protein kinase C-ERK1/2 signal pathway switches glucose depletion-induced necrosis to apoptosis by regulating superoxide dismutases and suppressing reactive oxygen species production in A549 lung cancer cells. J Cell Physiol 211: 371-385, 2007.

36. Gopalakrishna R and Jaken S: Protein kinase $\mathrm{C}$ signaling and oxidative stress. Free Radic Biol Med 28: 1349-1361, 2000. 